\author{
Ponomarenko V., \\ Pushanko N., \\ Khitriy Ya., \\ Liulka D., \\ Bahko E.
}

\title{
RESEARCH OF OPERATION OF LIQUID-GAS EJECTORS WITH COMPACT AND DISPERSED JETS OF LIOUID
}

\section{Проведено аналіз обладнання для сульфітащї иукрових розчинів. Виявлено недоліки роботи} струминного сульфітатора. Для встановлення закономірностей гідродинаміки двофазного потоку в камері змішування виготовлено експериментальну установку. Досліджувався ежектор 3 компактним та диспергованим струменем рідини. Встановлено оптимальну геометричну характеристику ежектора. Виявлено режим запирання за низьких тисків подачі рідини.

ключові слова: рідинно-газовий ежектор, коефіщієнт ежекцій, режим запирання, диспергований струмінь рідини.

\section{Introduction}

Ejectors are widely used in engineering as pumps, devices for various technological processes, heat pumps, air purifiers, etc. Their advantages in comparison with other equipment are the absence of moving parts, extreme simplicity of design, and high reliability of work Shortcomings are low efficiency [1].

Processes that can be implemented in the sugar industry in ejection device include:

- mixing of phase components (sugar juice and lime milk) for the subsequent process of defecation of the sugar solution;

- sulfitation of barometric water, juice and syrup, first and second carbonation, deammonification of condensates.

Ejection device is used for these processes only in a sulfitator for water, juice and syrup. Inkjet sulfitators were developed at the beginning of the last century [2], however, they did not find the proper application. In the 70 s of the XX century on the basis of new scientific achievements they were modernized and again proposed for carrying out sulfitations instead of bubbling and irrigation devices.

Their advantages are the intensity of mass-exchange processes, tens of times less specific metal capacity of devices, a significant reduction in sulfur dioxide emissions into the atmosphere.

However, jet sulfitator also have a number of shortcomings, caused both by the stability of the sugar factory as a whole and by the sulfitation station. The main reason is a constant change in the flow rate of the liquid, which leads to a frequent change of pressure on the nozzle, and consequently to the unstable operation of the ejection device. Because of this, it becomes difficult to maintain the optimal $\mathrm{pH}$ of the solution that is rigidly regulated by the technological process, low use of sulfur dioxide, which leads to corrosion of the exhaust pipe, sudden termination of ejection and, as a consequence, gas contamination of the room with sulfite gas.

Controlling emissions of sulfur dioxide into the atmosphere by the environmental service causes imposing penalties on the enterprise. Thus, technically, not perfection of equipment causes over-expenditure of both material and monetary resources that leads to an increase in the sugar cost.

The creation of more advanced equipment is possible only with a comprehensive study of the hydrodynamics of the water-gas flow in the mixing chamber of the ejector the main element of the jet sulfitation unit, which will make it possible to scientifically justify the dimensions of the sulfitator and its elements.

The wide introduction of ejectors in engineering for performing other technological tasks is restrained for the same reason - insufficient number of experimental studies of ejectors with a cylindrical mixing chamber and a compact or dispersed jet of liquid at low pressures of active flow.

\section{The object of research and its technological audit}

The object of research is a physical model of the ejection device of a jet sulfitator with a jet nozzle (compact jet of liquid) and a centrifugal jet (dispersed by a liquid jet).

Intense ejection devices in the sugar industry are not used as widely as one would expect. Perhaps this is due to the age-old traditional technology of sugar production, which is characterized by a low rate of chemical reactions and a significant duration of cleaning processes.

Analysis of the operation of jet sulfate plants at the sugar factory allowed to identify such problematic areas as the possibility of sulfur dioxide entering after the sulfur furnace into the working room, causing excess of the $\mathrm{SO}_{2}$ content in the air. Not full utilization of it worsens the ecological situation. The $\mathrm{pH}$ control of the solution treated in the sulfitator shows significant fluctuations from the specified technological regulations. The main reason is unsatisfactory work of the ejection device of the sulfitator.

Sulfur consumption in sugar production is quite significant: for one ton of raw materials, $0.25 \mathrm{~kg}$ for an irrigation sulfitator and $0.39 \mathrm{~kg}$ for a jet sulfitator [3, 4], and exceed similar costs in foreign plants [3].

In addition to the increased sulfur consumption, about $0.25 \%$ of the liquid is lost to the mass of beet, with the temperature dropping in the range $1.0 \ldots 1.4{ }^{\circ} \mathrm{C}[3]$ on the 
process with the spent sulfite gas. In work [5], there are proposed ways of utilization of sulfur dioxide and thermal emissions after a sulfitator for technological needs in the sugar production.

One of the ways to reduce losses is creation of more advanced equipment with rational geometric dimensions, which requires less reagents to carry out the process. This can only be with a comprehensive study of hydrodynamics and the identification of the features of the ejection device in the entire range of operating pressures. This approach will reduce the loss of both chemical and thermal potential due to the more complete use of $\mathrm{SO}_{2}$ from the sulfitating gas at its smaller total.

\section{The aim and objectives of research}

The aim of research is establishment of hydrodynamics laws of the water-gas emulsion flow in the mixing chamber of the ejector with an extended mixing chamber and a jet and centrifugal-jet nozzle.

To achieve this aim, the following tasks are accomplished:

1. To investigate the work of a typical sulfitator on a physical model and to reveal regularities and features of the flow of a water-gas emulsion.

2. To investigate the ejector operation with a dispersed liquid stream, reveal regularities and features of the water-gas emulsion flow.

3. To set the value of the geometrical characteristics of the ejectors, at which the maximum ejection coefficient is reached.

\section{Research of existing solutions of the problem}

A typical jet sulfitator for a medium-capacity sugar plant with a capacity of 3000 tons/day for the sulfitation of barometric water ПСК-3 (Smela Machine Building Plant, Ukraine) is a cyclone gas-liquid separator to which the ejection device is tangentially connected. As a working nozzle for liquid dispersion, a disk with five holes is used, it is formally a jet nozzles [6, 7], and a mixing chamber is a short cylindrical tube. A similar design has also sulfitators for juice and syrup (the difference is only in the number and diameter of the holes for dispersion of the liquid).

Each sulfitator can work as separately with an individual sulfur furnace and sublimator, and with a common gas collector. The operation of several sulfitators with a common gas collector is described in [8]. However, the hydrodynamics of the ejection device have not been properly investigated, which explains its shortcomings, revealed during the years of operation.

Traditionally, a jet nozzle is used in the ejection device as an active nozzle. Such devices have been widely studied [1, 9-15] both theoretically and experimentally. However, most of the known studies of ejectors have been carried out at high liquid pressures.

It should be noted that the sulfitation process is a mass-exchange process, for which not only the amount of gas consumed by the gas, but also the contact surface of the phases, is important.

The jet nozzle can't provide the necessary contact area of the phases, therefore it has been proposed to change the type of atomizer from jet to centrifugal jet or cav- itation [16]. This made it possible to improve the sulfitation process, and fundamental research that no effect was exerted on the effect of such a replacement on the hydrodynamics of the ejector.

For ejectors with a compact jet of liquid, correlations of the volume ejection coefficient are found for the example of $\mathrm{O}_{2}$ desorption from water into an inert gas [17]. It is established that the contact area of the phases increases from the velocity of the liquid in the nozzle, the maximum ejection occurs at a ratio of the throat diameter to the nozzle diameter of about 2, which coincides with the studies of other authors.

The study of ejectors with a dispersed jet of liquid is much less, for example, work [9]. The ejector was viewed in an upright position and with various liquid jets: cylindrical, twisted, cylindrical, not twisted, conical. It has been experimentally proved that the use of a swirling jet increases the mass transfer rate by $80 \%$.

Investigations of mass-exchange processes in ejectors with a compact and dispersed liquid stream during sulfitation of sugar solutions are not known. This does not allow to reasonably calculate the main geometric dimensions of the ejector during its design. The hydrodynamics of the water-gas emulsion flow in the mixing chamber of the ejector requires additional investigation.

\section{Methods of research}

To establish the regularities of a two-phase flow in an ejection device, a laboratory installation was designed and manufactured (Fig. 1). It consists of an ejection device with an extended mixing chamber 9, a receiving chamber 8 , a sprayer 7 and nozzles for supplying liquid and gas. The liquid in the sprayer 7 of the ejector is fed by a pump 1 under pressure, controlled by a pressure gauge 6 . The flow rate of the liquid is controlled by a tap 4 . Monitoring of the flow of liquid and gas is carried out using flow meters 5, 12 of the volumetric type. The rarefactions in the ejector are measured by a differential pressure gauge 11 .

The pressure is monitored using a spring type manometer ОБM1-160 (Ukraine). The flow rate of the liquid is measured by a water meter ETM KB 1.5 (Ukraine). Gas meter PREMA G 1.6 (Ukraine) is used to measure gas consumption. The vacuum in the intake chamber of the ejector is controlled by a differential pressure gauge. Photographing the flow of liquid in the mixing chamber is carried out with a digital camera Canon SX130 (China). The processing of the experimental data and the plotting of the graphs are performed using a Microsoft Office Excel spreadsheet.

The ejection device with a jet nozzle (Fig. 2) with nozzle diameter $d_{\mathrm{n}}=3,4,6,8 \mathrm{~mm}$ is investigated. The mixing chamber was transparent tubes of diameter $D_{\mathrm{m} c}=8,15,19,27,45 \mathrm{~mm}$. The liquid pressure varied within the range of $0.05 \ldots 0.25 \mathrm{MPa}$. Low liquid pressures are characteristic for the operation of pumps of the sugar plant and in particular the sulfitator.

Sulphitation process is associated with chemical reactions between the gas and liquid phases, requiring a large phase contact surface. It can be obtained by replacing the type of spray jet type with a centrifugal jet, characterized by the disintegration of the liquid jet at a small distance from the nozzle and the filled spray torch with droplets of liquid of 
the cross section. Therefore, the jet nozzle (Fig. 2) is replaced by a centrifugal jet (Fig. 3). To do this, the jet nozzle body is used, in which an insert with four inclined channels and a central hole is placed. Mixing chambers used the same.

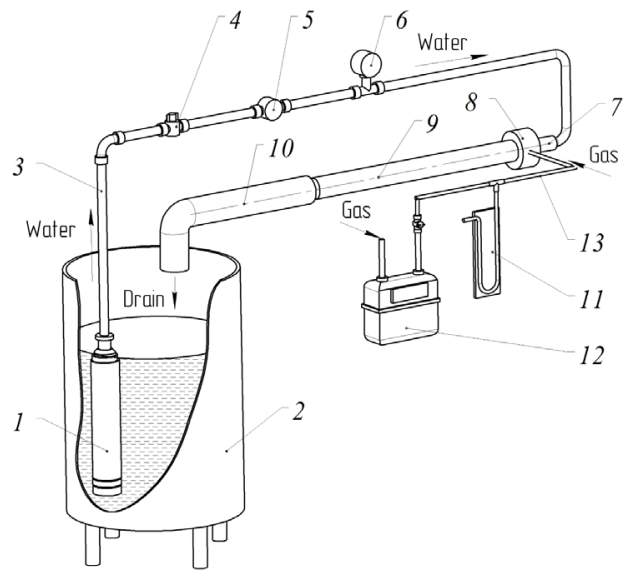

Fig. 1. Experimental device: 1 - pump; $2-$ measuring container; 3 - pipeline; 4 - tap; 5 - liquid flow meter; 6 - gauge; 7 - sprayer; 8 - receiving chamber; 9 - mixing chamber; 10 - drain pipe; 11 - gauge; 12 - gas flow meter; 13 - gas pipeline

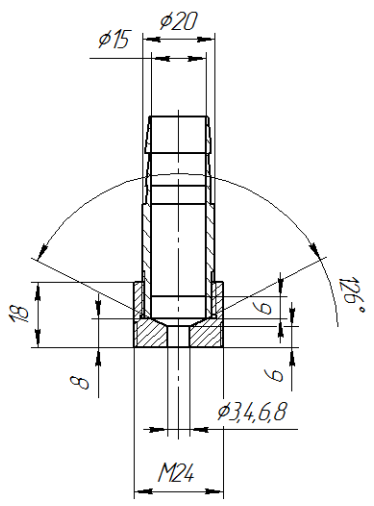

Fig. 2. Jet nozzle design

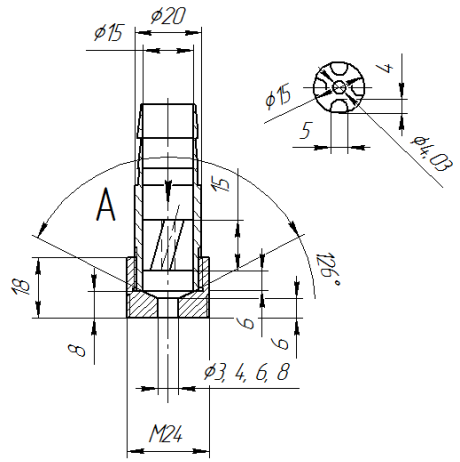

Fig. 3. Design of a centrifugal-jet nozzle with a central insert

To visually observe and photograph of the emulsion flow in a glass mixing chamber, the water circulating in the system is colored with food coloring.

The geometric characteristic of the ejector is the ratio of the diameter of the mixing chamber to the diameter of the active nozzle, $D_{\mathrm{m} . \mathrm{c}} / d_{\mathrm{n}}$.

The volume ejection coefficient $\mathrm{u}$ (the ratio of the flow rate of the passive flow to the flow rate of the active one) is determined by the formula:

$$
u=Q_{\text {gas }} / Q_{\text {liq }},
$$

where $Q_{\text {gas }}-$ gas flow rate, $\mathrm{m}^{3} / \mathrm{s} ; Q_{\text {liq }}$ - liquid flow rate, $\mathrm{m}^{3} / \mathrm{s}$.

\section{Research results}

6.1. Results of studies of an ejector with a compact liquid jet. A characteristic flow regime of a two-phase flow in a mixing chamber with a diameter of $45 \mathrm{~mm}$ with a jet nozzle with a nozzle diameter of $4 \mathrm{~mm}$ (geometric characteristic of the ejector 11.25) is shown in Fig. 4.

The geometric characteristic of the investigated ejector 11.25 coincides with its value for a typical sulfitator of the jet type (ПСК). Fig. 4 shows a qualitative picture of the liquid flow that is shows that with this geometric characteristic, the jet of liquid from the nozzle does not touch the walls of the mixing chamber.

The low eccentricity of the ejector is also affected by the reverse flow of liquid in the lower part of the glass tube, directed opposite to the main flow and caused by vacuum in the intake chamber of the ejector. The resistance of the inlet gas path exceeds the resistance of the gas inlet from the end of the mixing chamber. In a typical sulfitation plant, due to the reduced hydraulic resistance from the gas outlet to the atmosphere (due to the natural draft of the hot vapor-gas flow through the exhaust pipe), an insignificant ejection of the sulfitation gas is observed, the quality of the liquid treatment is low.

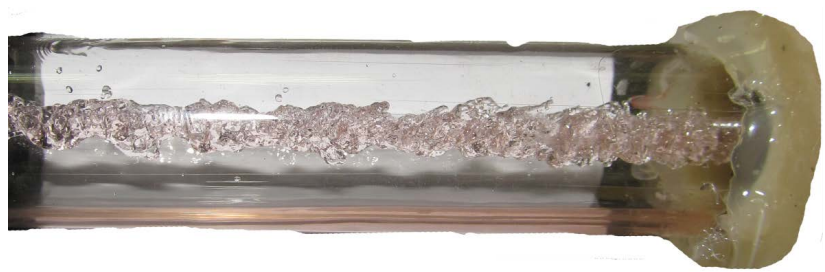

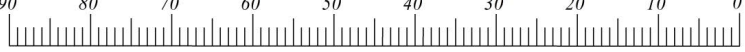

Fig. 4. Flow regime in the mixing chamber of a gas-liquid ejector with a geometric characteristic 11.25

To establish the numerical value of the geometrical characteristic of the ejector, at which the maximum ejection coefficient is reached, a study is carried out in the range of its variation 1.8...12.25, the results of which are shown in Fig. 5.

Research of the ejector with a geometric characteristic of $4.75\left(D_{m c}=19, d_{n}=4\right)$ shows that at a certain liquid pressure on the nozzle, the ejector is locked, that is, there is no ejection of the gas phase. Such regime is also found in the investigation of an ejector with a compact jet of liquid of other values of the geometric characteristic.

The mode of locking the ejector is described in [1, 9] at significant pressures of the active phase supply. In this case, the exhaust velocity from the nozzle of the injector is close to or greater than the speed of sound. At low ejector pressures, the locking mode was detected for the first time. A typical graph of the dependence is shown in Fig. 6.

The dependence of the rarefaction in the mixing chamber when the mixing chamber is horizontally placed on the pressure of the liquid on the nozzle is shown in Fig. 7. 


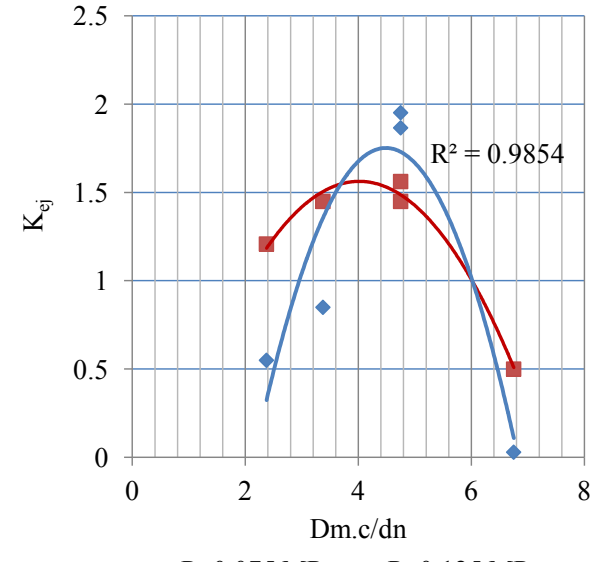

- $\mathrm{P}=0.075 \mathrm{MPa} \diamond \mathrm{P}=0.125 \mathrm{MPa}$

Fig. 5. Dependence of the volume ejection coefficient on $D_{\text {m. }} / d_{\mathrm{n}}$ ratio for an ejector with a compact jet at a pressure of supplying liquid to the injector nozzle

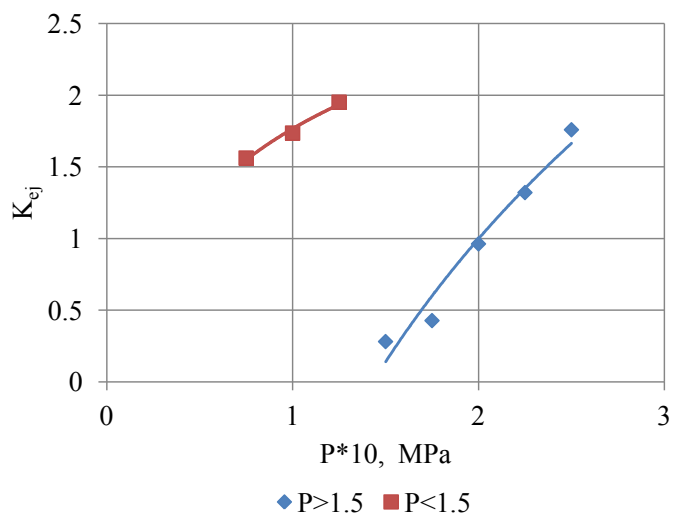

Fig. 6. Dependence of the volume ejection coefficient on the supply pressure of the liquid on the nozzle for $D_{m . c}=19 \mathrm{~mm}, d_{n}=4 \mathrm{~mm}$

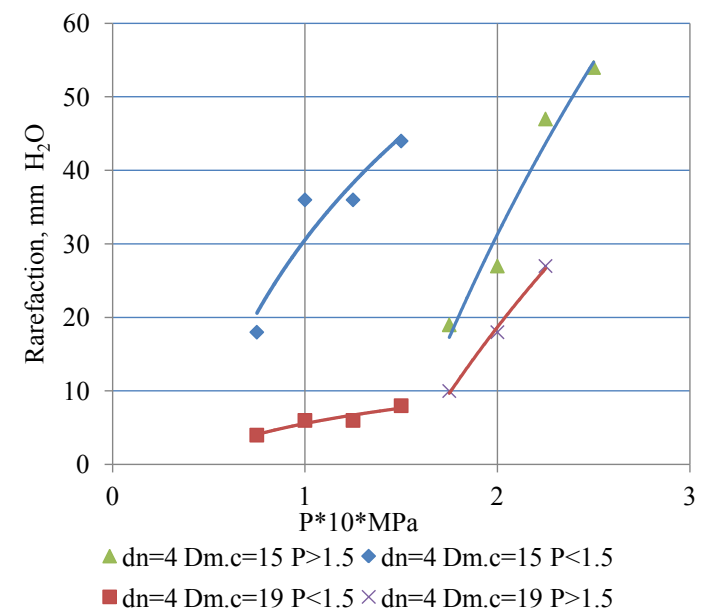

Fig. 7. Dependence of rarefaction in the mixing chamber on the pressure of the liquid on the nozzle

In the case of an increase in the supply pressure from the minimum to $0.15 \mathrm{MPa}$, the vacuum in the receiving chamber and the ejection coefficient increase. At a pressure of about $0.15 \mathrm{MPa}$, the ejector stops working (the locking mode) - the vacuum in the mixing chamber drops to zero. With a further increase in the supply pressure of the liquid into the nozzle of the injector to $0.3 \mathrm{MPa}$, the ejection and rarefaction coefficient again begin to increase. The locking mode occurs provided that the hydraulic resistance of the gas-phase supply path to the ejector is equal to the dilution in its receiving chamber.

6.2. Investigation of an ejector with a dispersed liquid jet. When the sprayer type was changed to a centrifugal jet nozzle, the flow regime of the emulsion in the mixing chamber changed qualitatively (Fig. 8). The opening angle of the spray of the sprayed liquid is about $40^{\circ}$ and the liquid touches the walls of the spray chamber.

Visual observation of the liquid flow in the mixing chamber of the ejector with $d_{n}=4 \mathrm{~mm}$ and $D_{m c}=27 \mathrm{~mm}$ shows the presence of significant backflows of liquid in the lower part of the mixing chamber to the nozzle of the injector. This, as in the case of using a jet nozzle as the working nozzle, leads to a decrease in the ejector efficiency. Return liquid flows are formed even when liquid droplets form. In Fig. 8, the trajectory of the droplet movement in the direction opposite to the trajectory of motion of the main mass of droplets due to rarefaction in the receiving chamber is noticeable.

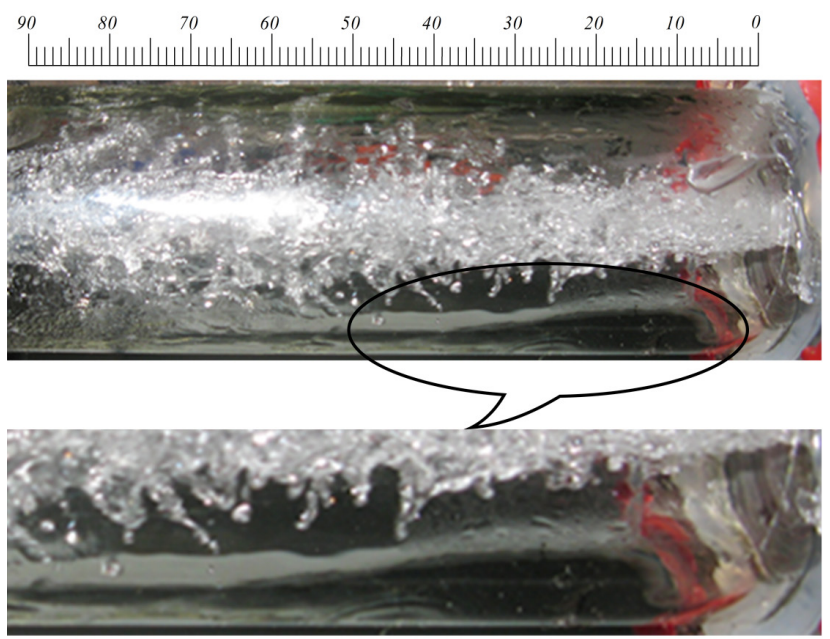

Fig. 8. Mode of a liquid flow at an exit from injector nozzle

The dependence of the volume ejection coefficient on the pressure of the liquid on the nozzle for $D_{m . c}=19 \mathrm{~mm}$ and $d_{n}=4 \mathrm{~mm}$ is shown in Fig. 9 .

From the graph in Fig. 9, it can be seen that the ejection coefficient increases with increasing liquid pressure at the nozzle (liquid flow increases). At a certain pressure of the liquid supply to the injector, the ejector becomes unstable, which is manifested in the termination of the absorption of the gas phase (locking mode). As in the case where the working nozzle is a jet nozzle, a discontinuity of the function is observed in the pressure range of $0.14 \ldots 0.17 \mathrm{MPa}$. At such liquid pressures, the ejector becomes unstable, which is manifested in the absence of ejection of the passive flow.

Similar dependences are found in the investigation of ejectors with a dispersed liquid jet and other geometric characteristics of $3.75\left(D_{m . c}=15 \mathrm{~mm}\right.$ and $\left.d_{n}=4 \mathrm{~mm}\right)$, $4.75\left(D_{m c}=19 \mathrm{~mm}\right.$ and $\left.d_{n}=4 \mathrm{~mm}\right), 6.75\left(D_{m c}=27^{n} \mathrm{~mm}\right.$ and $d_{n}=4 \mathrm{~mm}$ ) (Fig. 10). In this pressure range, the ejector locking mode is observed.

Research of ejectors with a different value of the geometric characteristic made it possible to find the dependence of the volume ejection coefficient on the main geometric parameter of the ejector (Fig. 11). The maximum value of the ejection coefficient is achieved in 
the range of values of the main geometric characteristic of the ejector $4 \ldots 7$.

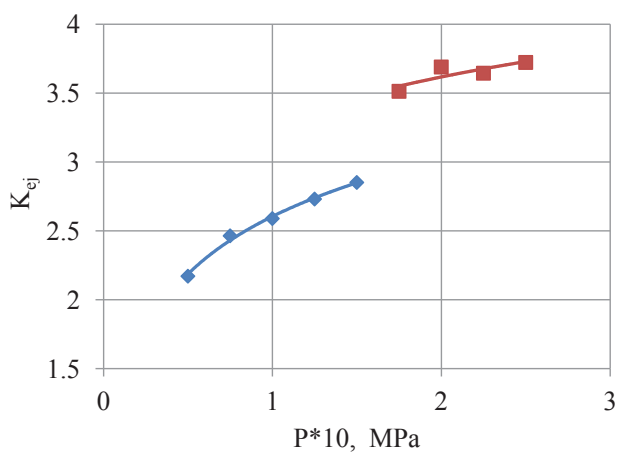

Dm.c $=19, \mathrm{dn}=4, \mathrm{P}<1.5 \quad$ Dm. $=19, \mathrm{dn}=4, \mathrm{P}>1.5$

Fig. 9. Dependence of the volume ejection coefficient on the liquid pressure on the nozzle

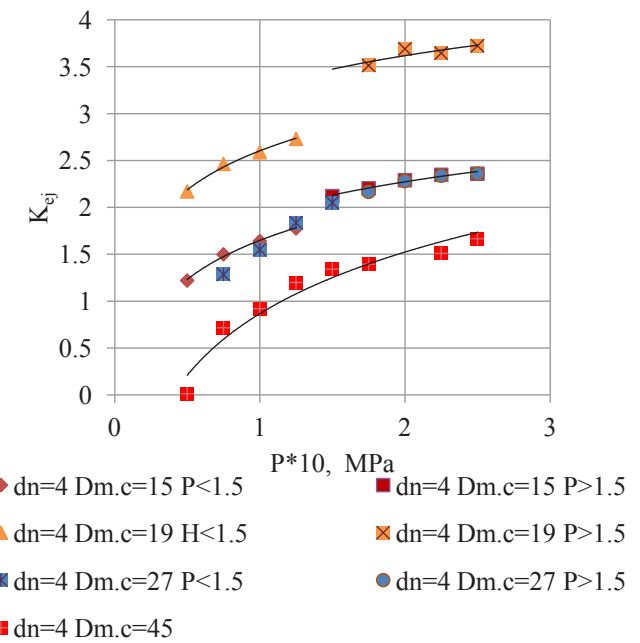

Fig. 10. Dependence of the volume ejection coefficient on the liquid pressure on the nozzle at $d_{n}=4 \mathrm{~mm}$ and $D_{m . c .}=15,19,27 \mathrm{~mm}$

An important characteristic of the ejector is the vacuum created in its receiving chamber. The dependence of the rarefaction in the mixing chamber when it is horizontally placed on the liquid pressure on the nozzle is shown in Fig. 12.

For a mixing chamber with a diameter of $49 \mathrm{~mm}$, the vacuum in the receiving chamber increases with an increase in the nozzle diameter from $4 \mathrm{~mm}$ to $8 \mathrm{~mm}$ (the value of the geometrical characteristic of the ejector is 6.12). The greatest value of rarefaction reaches at values of a geometrical characteristic of an ejector 4...6.

6.3. Ejector locking mode. When examining the ejector operation at low pressures of supplying liquid to the working nozzle of the nozzle $0.14 \ldots 0.17 \mathrm{MPa}$, there is a phenomenon of locking the ejector, in which the suction of the passive flow ceases. Such phenomenon is known at considerable flow velocities, called the resistance crisis and arises when the Reynolds numbers are of the order of $10^{5}[1,9]$. It is explained by the transitional regime of motion of the boundary layer, by shifting the lines of separation down into the aft region of the streamlined body.

New studies of the hydrodynamics of a two-phase flow in the spraying torch of a mechanical nozzle [18, 19] revealed the occurrence of a drop resistance crisis in the
Reynolds number $\operatorname{Re} \approx 40 \ldots 130$. The resistance crisis does not arise directly from the nozzle, where the phases actively interact, exchange impulse, and at a certain distance from the nozzle, where the interaction decreases, the fluxes of the pulses do not change and the radial profiles of the hydrodynamic characteristics are self-similar [18].

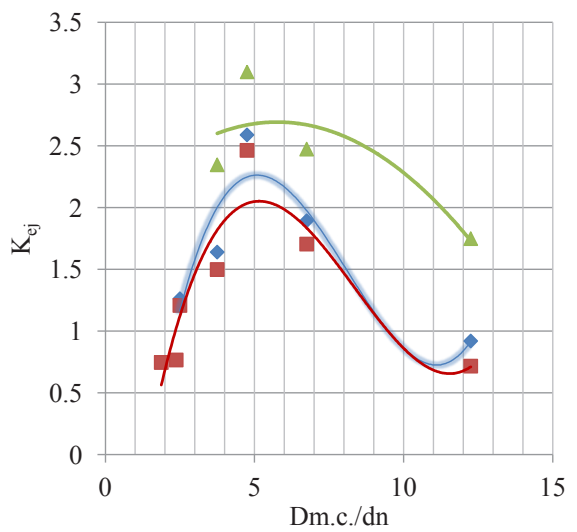

• $\mathrm{P}=0.1 \mathrm{MPa} \quad \mathrm{P}=0.075 \mathrm{MPa} \quad \triangle \mathrm{P}=0.225 \mathrm{MPa}$

Fig. 11. Dependence of the volume ejection coefficient on the main geometric characteristic $\left(D_{m . c} / d_{n}\right)$

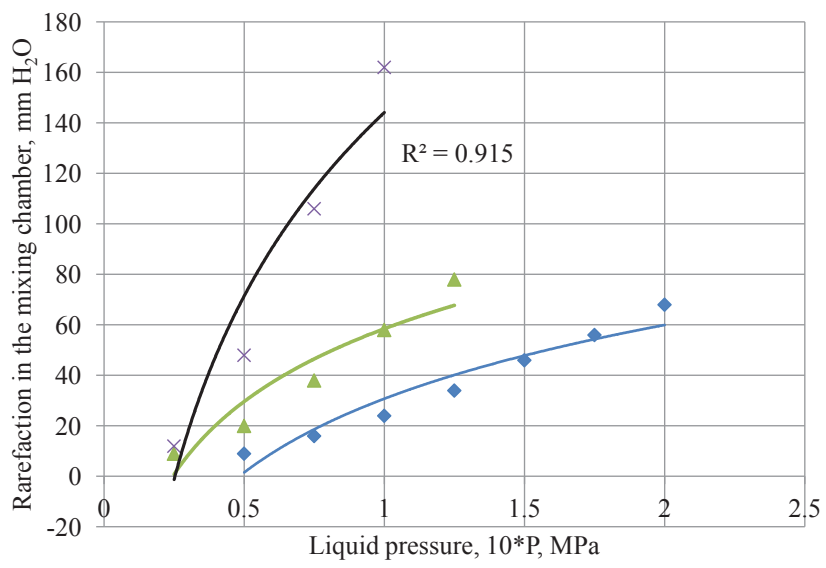

$\Delta \mathrm{dn}=4$, Dm. $\mathrm{c}=49 \Delta \mathrm{dn}=6$, Dm. $\mathrm{c}=49 \times \mathrm{dn}=8$, Dm. $\mathrm{c}=49$

Fig. 12. Dependence of rarefaction in the mixing chamber on the liquid pressure on the nozzle

The study of ejectors with a compact and dispersed liquid jet show a no-ejection mode (locking mode) at low liquid feed pressures, which is explained by the early resistance crisis.

Clearly the locking mode shows the values of the geometrical characteristic at which the maximum ejection coefficient is reached, and when it is removed from this value, it is weaker.

Dependence of the ejection coefficient on the flow rate of the liquid $K_{e j}=f\left(Q_{p}\right)$ Fig. 13 confirms the conclusion about the presence of a transient flow of water-air emulsion along the length of the mixing chamber of the ejector, which explains the mode of locking the ejector.

This conclusion is based on the fact that at the same flow rate of liquid through the nozzle within $0.00016 \ldots 0.00019 \mathrm{~m}^{3} / \mathrm{s}$ (with the liquid pressure at the nozzle was different), different ejection factors were achieved. For an example: when examining an ejector with $d_{n}=4 \mathrm{~mm}$ and $D_{m c}=$ $=19 \mathrm{~mm}$ at a liquid pressure $P_{P}=0.125^{n} \mathrm{MPa}$, its flow rate 
was $0.000183 \mathrm{~m}^{3} / \mathrm{s}$, and the ejection factor was 2.73. At a liquid pressure $P_{p}=0.2 \mathrm{MPa}$, the liquid flow rate was again the same, but the ejection factor increased to 3.69 . That is, with a pressure increase of 1.6 times, the liquid consumption did not change, the ejection factor increased by 1.35 times. Explain the work of the ejector can be given the early crisis of drop resistance at small $(\operatorname{Re} \approx 40 \ldots 130)$ values of the Reynolds criterion.

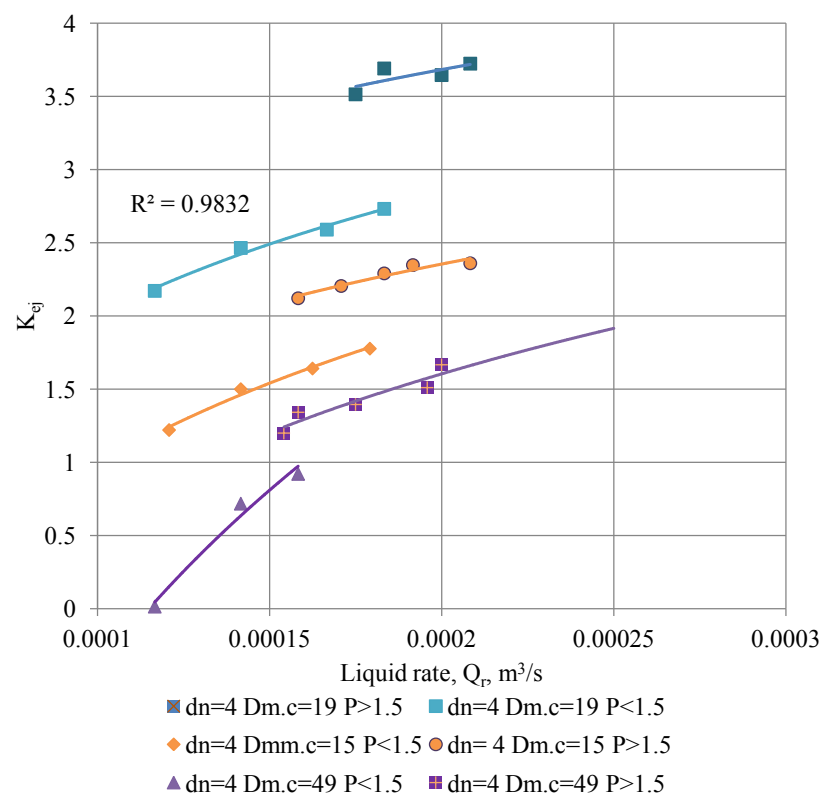

Fig. 13. Dependence of the ejection coefficient on the flow rate of the active flow

Research of an ejector with a jet nozzle as a working nozzle is due to the need to establish the causes of the unsatisfactory operation of the jet sulfitator in industrial conditions. This is manifested in the instability of the $\mathrm{pH}$ of the treated solution, the gassing of the working room with sulfitating gas, and low utilization of $\mathrm{SO}_{2}$.

The conducted studies (visual observations and on-site measurements) on a physical model with a geometric characteristic of the ejector 11.25 confirm the inefficient operation of the ejection device of a typical sulfitator due to the unjustified choice of the geometric dimensions of the ejector. A jet of liquid does not touch the walls of the mixing chamber, the presence of reverse liquid currents significantly reduces the ejection coefficient.

The maximum efficiency of the ejector is achieved by a geometric characteristic in the range 3...6, at which the largest ejection coefficient is reached. The increase in the pressure at which the liquid is sprayed also leads to an increase in the ejection coefficient.

In development of ejection devices in which the functions of ejecting the gas flow and conducting the target heat exchange processes are combined, it is of great importance that the contact surface of the phases acquires a suitable change in the type of spraying from centrifugal to centrifugal jet. The flow regime of the emulsion in the mixing chamber changes qualitatively.

The presence of significant backflows of liquid in the lower part of the mixing chamber to the injector nozzle shows that at low liquid pressures, the flow of the emulsion is not symmetrical across the cross section. It is necessary to take into account the task of the corre- sponding boundary conditions in mathematical modeling. Backflows of liquid are formed as a result of rarefaction in the intake chamber of the ejector.

The maximum value of the ejection and vacuum in the receiving chamber is achieved in the range of values of the main geometric characteristic of the ejector 4...7.

When investigating the operation of the ejectors at low pressures of supplying liquid to the working nozzle of the nozzle, the phenomenon of locking the ejector is observed, in which the suction of the passive flow ceases. As in the case where the working nozzle is a jet nozzle, a discontinuity of the function is observed in the pressure range of $0.14 \ldots 0.17 \mathrm{MPa}$. At such liquid pressures, the ejector becomes unstable, which is manifested in the absence of ejection of the passive flow.

It is possible to explain the mode of locking the ejector at low pressures by relying on the occurrence of a drop resistance crisis in the Reynolds transition numbers $\operatorname{Re} \approx 40 \ldots 130$.

\section{SWOT analysis of research results}

Strengths. The strength of the object of research is the simplicity of the equipment, and consequently the high reliability of operation, which causes their wide use in engineering. Their use in aeronautical engineering as the main element of jet engines stimulated research of ejectors at high flow velocities and a compact jet of liquid. The work is aimed at increasing the efficiency, which allows more efficient use of the energy of the compressed liquid.

Weaknesses. The work of the classical ejector at low pressures of liquid supply has been studied much less. And very few works performed for ejectors with a dispersed liquid jet and a cylindrical mixing chamber. The lack of reliable results leads to inefficient operation of the ejectors, which are already laid at the design stage. The work of a jet sulfitator at a sugar factory confirms what has been said. Unstable operation of the equipment, difficulties in maintaining technological requirements for the processed liquid, high sulfur costs for the process will require explanation and elimination of shortcomings. The received research results allow to explain low efficiency of work of jet sulfitators and allow to design more energy-saving equipment that works stably and allows to receive the processed liquid according to the technological regulations.

Opportunities. Further studies of the work of ejectors should be continued. In addition to the main geometric parameter, the places where the streams enter the mixing chamber, the length of the camera itself, etc. play an important role. Choosing the optimal geometric dimensions in the complex will lead to the creation of high-efficiency ejectors. Research and mass transfer are necessary when using ejectors that perform additional functions (for example, mass-exchange processes pass through the mixing chamber).

Threats. The imperfect work of the sulfitator led to the search for other ways of sulfitizing the products of sugar production. For example, to sulfite the liquids with sulfuric acid. However, in addition to the simplicity of dosing, this method does not have advantages over the sulfitation by anhydride sulphite, which is obtained by burning lump sulfur. Its reducing properties make it possible to conduct appropriate chemical reactions, sterilize the liquid. In general, a qualitative and effective treatment is obtained. 


\section{Conclusions}

1. An investigation of ejectors with a compact liquid jet in the range of variation of the geometrical characteristic of the ejector is 1.3...11.25 and their values are found at which the maximum ejection coefficient is reached. The numerical value of this coefficient depends on the supply pressure to the nozzle of the active jet and increases with its increase. At a liquid pressure on the nozzles $P=1.2510^{5} \mathrm{~Pa}$, the ejection coefficient reaches a numerical value of 2.0 .

2 . The value of the geometrical characteristic of the ejector with a dispersed liquid jet (4...7) is established, at which the maximum ejection coefficient is reached. As the pressure of supply of liquid to the nozzle of the injector increases, the numerical value of $K_{e j}$ increases (at a pressure $P=0.225 \mathrm{MPa}$, the ejection coefficient reaches 3.5). $K_{o j}$ exceeds the same figure for an ejector with a compact liquid jet at $15 \ldots 20 \%$.

3 . The ejector locking mode is detected, described and explained at low pressures of the liquid supply to the nozzle of the injector. The locking mode occurs when the resistances of the underwater gas path are equal and the movement of the water-air emulsion in the mixing chamber of the ejectors is equal. For the investigated ejectors, the closing mode of the next one after the liquid supply pressure is $0.14 \ldots 0.17 \mathrm{MPa}$.

\section{References}

1. Aleksandrov, V. Yu. Optimal'nye ezhektory (teoriia i raschet) [Text] / V. Yu. Aleksandrov, K. K. Klimovskii. - Moscow: Mashinostroenie, 2012. - 136 p.

2. Apparatus for the continous sulfuration of sugar-juices [Electronic resource]: Patent US 789372 A / Maguin A. - Filed March 4, 1904; Publ. May 9, 1905. - Available at: \www/ URL: https://www.google.com/patents/US789372

3. Razladin, Yu. S. Spravochnoe posobie po ekonomii toplivnyh energoresursov na predpriatiiah pishchevoi promyshlennosti [Text]. Book 1. Proizvodstvo sahara / Yu. S. Razladin, S. Yu. Razladin. - Kyiv: Osvita Ukraina, 2010. - 582 p.

4. Vyskrebtsov, V. B. Utilizatsiia sernistogo angidrida i rashod sery [Text] / V. B. Vyskrebtsov // Sahar. - 2003. - No. 5. P. 46-48.

5. Ponomarenko, V. Development of equipment and technological schemes to reduce emissions of sugar factory [Text] V. Ponomarenko, N. Pushanko, N. Pushanko // Technology Audit and Production Reserves. - 2015. - Vol. 4, No. 4 (24). P. 35-41. doi:10.15587/2312-8372.2015.47018

6. Grebeniuk, S. M. Tehnologicheskoe oborudovanie saharnyh zavodov [Text] / S. M. Grebeniuk. - Moscow: KolosS, 2007. 520 p.

7. Azrilevich, M. Ya. Oborudovanie saharnyh zavodov [Text] M. Ya. Azrilevich. - Ed. 3. - Moscow: Legkaia i pishchevaia promyshlennost', 1982. - 392 p.

8. Ponomarenko, V. Ejection devices in mass transfer processes of sugar industry [Text] / V. Ponomarenko, N. Pushanko. - Saarbrucken: LAP LAMBERT Academic Publishing, 2014. - $56 \mathrm{p}$.

9. Tsegelskii, V. G. Dvuhfaznye struinye apparaty [Text] / V. G. Tsegelskii. - Moscow: MSTU n. a. N. E. Bauman, 2003. - 408 p.

10. Bouhanguel, A. Flow visualization in supersonic ejectors using laser tomography techniques [Text] / A. Bouhanguel, P. Desevaux, E. Gavignet // International Journal of Refrigeration. - 2011. - Vol. 34, No. 7. - P. 1633-1640. doi:10.1016/j. ijrefrig.2010.08.017

11. Riffat, S. B. Recent development in ejector technology - a review [Text] / S. B. Riffat, L. Jiang, G. Gan // International Journal of Ambient Energy. - 2005. - Vol. 26, No. 1. P. 13-26. doi:10.1080/01430750.2005.9674967

12. Kandakure, M. T. Hydrodynamic aspects of ejectors [Text] M. T. Kandakure, V. G. Gaikar, A. W. Patwardhan // Chemica Engineering Science - 2005 - Vol. 60, No. 22 - P. 6391-6402. doi:10.1016/j.ces.2005.04.055
13. Li, C. Configuration dependence and optimization of the entrainment performance for gas-gas and gas-liquid ejectors [Text] / C. Li, Y. Li, L. Wang // Applied Thermal Engineering. - 2012. - Vol. 48. - P. 237-248. doi:10.1016/j.applthermaleng.2011.11.041

14. Cramers, P. H. M. Influence of the ejector configuration, scale and the gas density on the mass transfer characteristics of gas-liquid ejectors [Text] / P. H. M. Cramers, A. A. C. Beenackers // Chemical Engineering Journal. - 2001. - Vol. 82, No. 1-3. P. 131-141. doi:10.1016/s1385-8947(00)00363-6

15. Park, B. H. Fluid dynamics in starting and terminating transients of zero-secondary flow ejector [Text] / B. H. Park, J. H. Lim, W. Yoon // International Journal of Heat and Fluid Flow. 2008. - Vol. 29, No. 1. - P. 327-339. doi:10.1016/j.ijheatfluidflow.2007.06.008

16. Method of sulfitation of sugar production fluids [Electronic resource]: Patent UA 39000 A / Vyskrebtsov V. B. - Appl. No. 2000127519; Filed December 26, 2000; Publ. May 15 2001, Bull. No. 4. - Available at: \www/URL: http://uapatents. com/4-39000-sposib-sulfitaci-ridin-cukrovogo-virobnictva.htm

17. Kislov, E. A. Optimizatsiia protsessa massoobmena v struinom apparate [Text] / E. A. Kislov, A. V. Sugak, D. O. Bytev, A. S. Gribanov // Izvestiia VUZov. Seriia «Himiia i himicheskaia tehnologiia». - 2005. - Vol. 48, No. 2. - P. 91-93.

18. Simakov, N. N. Krizis soprotivleniia kapel' pri perehodnyh chislah Reinol'dsa v turbulentnom dvuhfaznom potoke fakela raspyla mehanicheskoi forsunki [Text] / N. N. Simakov // Zhurnal tehnicheskoi fiziki. - 2004. - Vol. 74, No. 2. - P. 46-51

19. Simakov, N. N. Raschet soprotivleniia i teplootdachi shara obtekaiushchemu gazu v tsilindricheskom kanale [Text] N. N. Simakov // Zhurnal tehnicheskoi fiziki. - 2016. Vol. 86, No. 9. - P. 32-38.

\section{ИССЛЕДОВАНИЕ РАБОТЫ ЖИДКОСТНО-ГАЗОВЫХ ЭЖЕКТОРОВ С КОМПАКТНОЙ И ДИСПЕРГИРОВАННОЙ СТРУЕЙ ЖИДКОСТИ}

Проведен анализ оборудования для сульфитации сахарных растворов. Выявлены недостатки работы струйного сульфитатора. Для установления закономерностей гидродинамики двухфазного потока в камере смешивания изготовлена экспериментальная установка. Исследован эжектор с компактной и диспергированной струей жидкости. Установлена оптимальная геометрическая характеристика эжектора. Выявлен режим запирания при низких давлениях подачи жидкости.

ключевые слова: жидкостно-газовый эжектор, коэффициент эжекции, режим запирания, диспергированная струя жидкости

Ponomarenko Vitaly, PhD, Associate Professor, Department of Technological Equipment and Computer Technology Design, Educational-Scientific Engineering-Technical Institute named after Acad. I. S. Guly, Kyiv, Ukraine, e-mail:vponomarenkov@ukr.net, ORCID: http://orcid.org/0000-0002-0732-4783

Pushanko Nicholas, Doctor of Technical Sciences, Professor, Department of Technological Equipment and Computer Technology Design, Educational-Scientific Engineering-Technical Institute named after Acad. I. S. Guly, Kyiv, Ukraine, e-mail: npychankon@i.ua, ORCID: http://orcid.org/0000-0002-7151-9657

Khitriy Yaroslav, Postgraduate Student, Department of Technological Equipment and Computer Technology Design, Educational-Scientific Engineering-Technical Institute named after Acad. I. S. Guly, Kyiv, Ukraine, e-mail: h.yaros.s@gmail.com, ORCID: http://orcid.org/ 0000-0002-1661-7377

Liulka Dmitriy, PhD, Associate Professor, Department of Technological Equipment and Computer Technology Design, Educational-Scientific Engineering-Technical Institute named after Acad. I. S. Guly, Kyiv, Ukraine, e-mail: lulkadm@ukr.net, ORCID: http://orcid.org/ 0000-0001-8014-5776

Babko Eugene, PhD, Associate Professor, Department of Technological Equipment and Computer Technology Design, Educational-Scientific Engineering-Technical Institute named after Acad. I. S. Guly, Kyiv, Ukraine, e-mail: babkoe@ukr.net, ORCID: http://orcid.org/ $0000-0003-2389-007 X$ 